\title{
Body and dieting concerns of pre-adolescent South African girl children
}

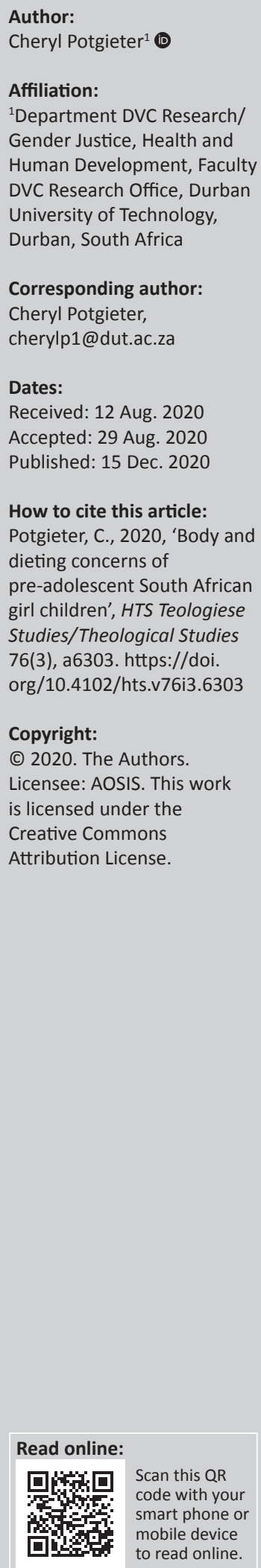

There has been an increase in research that focuses on female adolescents and adult women concerns relating to body image and dieting concerns. However, research on body and dieting concerns of specifically pre-adolescents is still a neglected area of research in comparison with female adolescents and adult women. Pre-adolescents are either research participants as part of a group, which includes younger children, or part of a group of adolescents. This article addresses the body and dieting concerns of pre-adolescent females as a group on their own. A qualitative study was conducted, and data were collected by using a vignette with semistructured questions. The data were analysed by using a thematic analysis. The results indicated that although the girls presented a 'polite' discourse that all girls should be accepted irrespective of weight, when they were futher engaged with during the interviews this was not reflective of their world view. Negative attributes were projected onto the heavier girl in the vignette, and the discourse of acceptance was linked to feelings of pity and sympathy as fat girls were 'handicapped' albeit not because of their own doing. Thin girls were linked to positive traits, such as kind, happy and with leadership potential. The pre-teens in the sample were all very familiar with terms related to food restrictions (dieting), and a number of them had indulged in dieting behaviour to lose weight. The research was conducted in one province in South Africa and provides baseline data for a bigger study, which includes other provinces, as well as girls from rural areas and girls from schools in poorer urban areas. The results indicated that the pre-teen girls have internalised gendered notions of what it means to be female and being thin is integrally linked to what patriarchy has constructed as the ideal female body.

Contribution: This article is grounded within the discipline of Psychology. However, the scholarly contribution it intersects with include the disciplines of Public Health, Education and Gender Studies. It provides and engages a discourse at the intersections of the Social Sciences and Humanities disciplines, contributing to knowledge which is interdisciplinary and multidisciplinary.

Keywords: Body dissatisfaction; Body image; Dieting; Female girls; Girl children; Pre-adolescents; South Africa.

\section{Introduction}

Over the past four decades, a body of work has emerged, which advocates that the views that children and adolescents hold regarding the body image are moulded in their early childhood. Body image has multiple definitions, but there is a general understanding that it refers to our feelings, attitudes, beliefs and perceptions, which we have about our bodies. Body image cannot be essentialised as it emerges from an active relationship between individual, body and the lived environment. Girl children in western settings are from a very young age exposed to a discourse that being labelled as pretty, cute and generally physically attractive will translate into being happy, clever and wealthy. This is as an 'appearance culture' (Tregels \& Eggermont 2017), which puts immense importance on the thin body, and thus a thin person is predominantly viewed in a positive light.

Children in the age group of 9-12 years have often not been researched on exclusively as a separate group, but have been either part of a younger age group or part of a slightly older group. There is a recognition of the paucity of studies in the area specifically dedicated to childhood (Neves et al. 2017). This group of 'tweens' is the focus of the research in this article. Much of the research has been conducted in urban settings, but there has been an increase in research conducted in rural settings (Pedro et al. 2016). 
Gender differences regarding body image concerns exist from a very young age, with girls reporting higher body image dissatisfaction compared with boys (Ricciardelli \& McCabe 2001). Research findings have found that there is an increase of preadolescent girls endorsing the sentiment that they have to limit what they eat to lose weight, as only then they will meet societal expectations (Russo \& Spahr 2011). Trekels and Eggermont (2017) point out that researchers have referred to a dysfunctional appearance belief culture when preadolescents believe, for example, that their physical attributes determine their value as a person. The latter belief is deemed dysfunctional, and it contributes to eating disorders and body dissatisfaction (Spangler 2002). Young adolescents who hold a dysfunctional world view of physical appearance have a high risk of being dissatisfied with their bodies and developing disordered eating behaviours (Trekels \& Eggermont 2017). Dissatisfaction with body image also increases the risk of eating disorders and depression (Lawler \& Nixon 2011).

The research literature on the topic of body image has found that females are subjected to societal pressures regarding the thin ideal more often than males (Grogan 2008; Levine \& Smolak 1996). The pressure starts at a young age and continues into adulthood. Brown and Slaughter (2011) investigated the issue of physical attractiveness and normality in a sample of girls and women whose ages ranged from 4 to 26 years. They found that the sample across all the age categories rated pictures of underweight women as more attractive than those of women who they deemed to be of a regular weight.

Gender differences regarding body image concerns already exist at a very young age, with girls reporting higher body image dissatisfactions compared with boys (Collins 1991; Lawrence \& Thelen 1995; Ricciardelli \& McCabe 2001). These findings highlight the prevailing and often unrealistic constructions of how the female body should look.

This study aimed to explore the body and dieting concerns of preadolescent South African girl children. More specifically, the research focussed on the body concerns of preadolescent girls, and how they viewed their own and other bodies, to explore their experience of and reasons for body satisfaction and body dissatisfaction. Dieting awareness and behaviour were also explored. 'Preadolescent' refers to children between the ages of 9 and 12 years (Meyer \& Van Ede 2001). Dieting behaviours for the study refer to eating practices that intentionally restrict food intake. This may also include behaviours such as purging and excessive exercise with the intent to lose weight (Kostanski \& Gullone 1999).

Body concerns were conceptualised as the broad term used to explore concerns relating to the body, and this included overall body image, aspired body ideal and the level of current body satisfaction as well as dissatisfaction. These aspects can and were also viewed separately. Body image satisfaction/dissatisfaction was engaged with as the complex interaction between internal-biological, psychological and external social factors all relating to the eventual mental representation of the body (Blyth et al. 1985; Hutchinson 1985; Petersen et al. 2006). The aspired body ideal refers to the ideal shape that the individual wants for herself, and this may be similar to, larger than or thinner than her current body size.

\section{Methodology \\ Recruitment}

Purposive sampling was used to recruit the sample. The primary goal of the sampling method used is to focus on specific characteristics of the group, which is of interest to the researcher as they will be the most suitable to respond to the research aims and questions. In this research, preadolescent girls between the ages of 9 and 12 were the group that was required to be engaged with as they were 'information-rich' and they offer crucial information relating to the phenomenon of interest (Patton 2002).

The recruitment was carried out by approaching persons who were likely to have a daughter or acquaintance in this particular group. In qualitative research, this method is very applicable as cases for study. Sampling is aimed at insight and rich descriptions about the phenomenon, not an empirical generalisation from a sample to a population. The sample size then becomes superfluous as each case is treated as unique and important (Patton 2002).

Once a girl was 'found' who fitted the respondent profile, the mother of the potential respondent was approached. This was performed by calling the mother of the prospective participant and explaining the purpose of the research to her. As the participants were all children, legal consent was required from the parent. However, a child assent form was also provided, explaining the process to the girl to make sure that she was in fact willing to participate in the research. The parent and girl were given the consent form to read and sign before the interview could commence.

\section{Sample and participant details}

It was decided not to gather biological information, such as weight and height, as it would not be constructive to the research process or to the experience of the process of the girls. Information on the parental background was collected. Both black and white respondents were recruited, to have perspectives from girls with 'differing' racial backgrounds, as differences had been noted in previous research. The final data set included six black respondents and five white respondents. The girls all attended similar schools in Pretoria and Johannesburg, and based on their parents' profile, they would all be classified as middle class.

The sampling was restricted to the Gauteng province in the greater Pretoria and Johannesburg area. 


\section{Data collection tools}

Data were collected by means of in-depth interviews by using a vignette. Hazel (1995:2) defines the vignette as 'concrete examples of people and their behaviours on which participants can offer comment or opinion'. The vignette was used as a way to start the conversation with the girls and was accompanied by pictures (see the later paragraph).

This technique was also useful as the participants were young and may have difficulties articulating their experiences through direct questioning and also in environments where the topic is of a sensitive nature. The vignette provides a realistic, yet safe, environment for the participants to express themselves (Barter \& Renold 2000; Gourlay et al. 2014).

In addition, the vignette was chosen as the most suitable way of data collection, as it eliminates over-claim and social desirability, which can be associated with direct questioning, especially in the case of younger children (Pine 2001). This technique is also often associated with the qualitative paradigm, as it offers participants the opportunity to define social situations in their own words and on their own terms (Finch 1987).

Children are worthy of being researched in their own right and not only in relation to how adult researchers conceptualise their life world (Barter \& Renold 2000). The use of the vignette thus gave the girls an opportunity to express their experiences and feelings in their own subjective way. The vignette was administered along with pictures of girls with different body shapes. Two sets of pictures were used. One set included two white girls, one who would be viewed as 'thin' and another 'overweight' by western societal standards. The other set included two black girls, one 'thin' and another 'overweight' by western standards. The pictures were generic 'stock photos' gathered from an online image library.

Girls were given a brief hypothetical scenario, which included giving the girls in the pictures names, mentioning that they also went to a similar school as the girls being interviewed and that the girls enjoyed going to the movies. The discussion was started by asking what the participants thought the girl bought at the movies and what type of movies she likes, before delving into what 'kind' of a girl she is, what her likes and dislikes are and how she felt about her body.

The vignette was semi-structured and provided a 'starting block' into the questions. The researcher facilitated discussion around the opinions and comments expressed by the participant to the point where the researcher felt saturation had been reached in the interview.

\section{Pilot interview}

A pilot interview was conducted to test the flow of the data collection instrument and to determine whether the vignette that had been prepared made sense to the preadolescent girl. The pilot proved crucial as the initial expectation was to interview each girl for approximately $1 \mathrm{~h}$. However, after the pilot interview, it was realised that the interview was much shorter and that keeping the attention of the child became more difficult, the longer the interview went on.

With the latter in mind, subtle changes were made to the vignette to ensure it was brief and concise but still allowed for in-depth insights to emerge. It was decided to include the pilot interview in the final data set. Including the pilot, a total of 11 interviews were carried out.

\section{Data collection procedure}

Girls were interviewed on a one-on-one basis to allow the researcher to establish rapport with the participant and without the distraction from other participants. The mothers were not present during the interview for the same reasons. Interviews were conducted in the homes of the respondents or in a school classroom if the interview took place directly after school. Prior to the interviews, the researcher enquired as to the language of choice to be interviewed in. The interviews were conducted in English.

Permission was requested from the girl for the interview to be recorded in the child assent form, and this was established again before the interview commenced. In addition to the recording, detailed notes were taken. After data collection, the data were transcribed verbatim, whilst listening to the recordings. The transcriptions along with the relevant field notes were compared for the analysis procedure.

\section{Ethical considerations}

During the proposal phase, ethical clearance was obtained from the ethics committee of the university where the researcher was attached to.

These matters are crucial and 'more so' because of the research involving children and a topic that is deemed to be sensitive. Informed consent and confidentiality were given much thought and were maintained with great care.

Informed consent was obtained from both the girl and her parent (in all instances, it was the mother) by means of the informed consent form approved by the university. These forms informed the participants and the mother of the purposes of the research their right to decline participation and the right to withdraw at any stage, the potential consequences of participating in the research, the benefits of the research and the confidentiality of the research.

In the consent form, permission was also obtained from the parent to record the interview. The researcher's contact number was also provided should they required additional information or needed to contact the researcher. The ethics committee also required an assent form for the girls participating. The latter was necessary to provide them with the detailed information of the research and the purposes for which it was conducted. 
The form was written in simple language, and the girls were asked to sign the form. Although this assent did not hold any legal purposes, it was used mainly to provide the girl with the opportunity to decline to participate and to make sure she understood what the research was for and how she would be involved. The latter was again explained before the interview commenced.

Permission from the child to record the interview was also obtained in the assent form, but also informally again before the interview commenced. One of the main purposes of the informed consent is to inform the participants that participation is completely voluntary and that they have the right to decline to participate and terminate the interview at any stage, without any consequences to them personally (Brinkmann \& Kvale 2008).

Also discussed in the informed consent form were matters such as who would have access to the results and how they would be used. This was explained in a simplified manner to the girls, whilst their mothers were provided with appropriate information regarding the nature of the study and how the results were to be disseminated. Another ethical consideration was confidentiality. According to Brinkmann and Kvale (2008), anonymity should be explained to participants, and they should be reassured that no identifiable characteristics would be revealed at any stage throughout the research. This was explained in both the child assent and informed consent forms, and participants were again reassured before commencing the interview that what they say will not be linked to them personally in any way, so they can be honest and candid.

To ensure this, each participant was given a number and throughout the research she was referred to by the number allocated. Where participants mentioned the names of friends or family, the names were removed. At the end of the interview, participants were also debriefed by once again explaining the purpose of the research and how they had contributed. They were also thanked for their co-operation. Brinkmann and Kvale (2008) concurred with this and placed importance on the consequences of the research and the researcher's roles to address these consequences. Qualitative interviews, especially in psychology, can often result in 'quasi-therapeutic relationships', especially when a sensitive matter is discussed (Brinkmann \& Kvale 2008:267). In the current research, the interview did not develop into a 'quasitherapeutic' relationship.

It is the researcher's role to be mindful of these potential situations to minimise the potential harm of participating. Body image can become a sensitive topic, especially when possible eating disturbances are present.

\section{Data analysis}

After data collection, the recorded interviews were transcribed and read repeatedly. The transcriptions were compared with the field notes made during data collection and also to the literature read. This allowed the researcher to make sense of the volume of information to identify the themes and patterns prevalent in the data. Data were then analysed by means of a thematic data analysis. This analysis entails searching for themes that emerge from data pertaining to a specific phenomenon (Fereday \& Muir-Cochrane 2006). After repeatedly reading the transcribed material, the interviews were organised into broad categories relating to overall body satisfaction.

This served as a starting point to find the underlying relationships and shared meaning. After following a colourcoding approach to make sense of the data, certain parts of the transcriptions were coded, and these codes and verbatim interviews were organised into a Microsoft Excel sheet to further disaggregate the data. The Excel sheet included the code number, code name and verbatim response. This allowed a systematic view of the data. Subsequently, codes were grouped together as they proved to be similar, and as a final step, the consolidated codes were grouped into themes and named accordingly. To ensure that the generated themes were relevant and coherent, the themes were compared with the research questions and the available literature. After spending a considerable time analysing the data, it was interpreted and organised according to the emergent themes and their salient characteristics, and the interconnectedness of the various themes was highlighted.

\section{Contradictions in downplaying the importance of appearance}

The results revealed a paradox between what girls directly expressed when it came to the importance of beauty, appearance and weight and what their perceptions and ultimate behaviour suggest regarding issues of beauty and weight.

Girls were asked whether they thought appearance and weight were important. Many of the girls referred to their conviction that God made everyone beautiful.

The majority of the girls verbalised that weight and appearance are not important, and that beauty cannot be measured by these factors alone. The following illustrates the point:

'It does not matter how you look; you can still be a friend; you don't have to play with a thin or fat child.' (female, age unspecified, date unspecified)

However, the verbalisation that it was not important to be thin was not always supported by the data, which the conversations produced. The discourse that God created all people and they should be accepted was not an unconditional acceptance, and it was underpinned by a discourse of pity and within a framework of a disability being seen as a deficit.

The following statement highlights the conflict:

' $[N] \mathrm{o}$, it is not important, but fat people ... I feel sorry for them. I want them to be thin like us ... Jesus made them and handicapped children.' (female, age unspecified, date unspecified) 
Only two girls verbalised 'directly' that it was important to look a certain way and stated:

'[T] hey must be a little bit thin and not too fat. It does matter [how you look], thin people are a little sexier.' (female, age unspecified, date unspecified)

Both these girls were slightly 'heavier' than the majority of the girls interviewed, and it is possible that they perhaps experience the pressure to be thin more intensely compared with the other girls. The literature suggests that girls with a higher body mass index (BMI) are more likely to experience higher levels of body dissatisfaction and will subsequently have a stronger desire to be thin (Gardener et al. 1997; Hansson \& Rasmussen 2010; Vander Wal \& Thelen 2000).

Girls with a higher BMI are also more likely to receive direct messages regarding their weight status like being encouraged by their parents to alter their eating behaviours or to engage in dieting practices (Berge et al. 2013; Thelen \& Cormier 1995).

These children are also more susceptible to indirect messages stemming from peers and media about weight and as a result compare themselves with others, increasing the likelihood of body dissatisfaction (Lawrie et al. 2006; Stice, Maxfield \& Wells 2003).

It is concerning that there was a discourse which constructed being overweight as a disability and the disability was seen as one that needed pity. The norm was to be thin and whilst they accepted girls who were overweight, it was not what they wished for. Overweight girls are perceived as physically 'abnormal' and are seen to need sympathy.

It further emphasises the contradiction between what girls are supposed to believe about those who are overweight (that weight does not matter) and the stereotypes that are already entrenched at this age.

As the following results indicate the verbalisation that 'it is ok to be fat' and that 'fat girls should be accepted' is the polite response, but further engagement indicates that it is not what they 'believe'.

\section{We accept the fat you but you would be happier if thin}

The majority of girls responded that the heavier girl in the picture did not have control over the fact that she was overweight and that she was probably born that way and her being fat was beyond her control.

There was also the assumption that she may be sad and there was a discourse of blame linked to the mother.

Responses included:

' $[I] \mathrm{t}$ makes her feel sad because she knows that she was born like that.' (female, age unspecified, date unspecified)

'[M]aybe she took her mother's body.' (female, age unspecified, date unspecified)
A discourse also emerged where participants were of the opinion that sometimes, not always girls had similar bodies to their mothers. When asked how do they know this, it emerged that mothers and their peers at school had told them this.

The statement that 'she probably likes yummy sweet stuff and food that she can't help herself' was not a dominant discourse or sentiment and even then, it was linked to the fact that it was beyond her control.

However, there was pity that this situation was beyond her control and that she would be much happier if she was thin:

'If she loses weight, she could be happy, and boys would love her.' (female, age unspecified, date unspecified)

'[T]hen more people can like her [if she loses weight] and she can be proud that she actually lost weight.' (female, age unspecified, date unspecified)

These responses again indicate that the respondent's initial answer that weight makes no difference was a polite, socially accepted response.

A dominant discourse that emerged from the conversations was that if the girl in question lost some weight, she would be much happier, and in some instances, more liked.

There is also the underlying belief that they are pitied but accepted, and that the overweight girl is disabled, desiring a 'normal' body and they are pitied.

The word normal came up very often, and it was linked to a desire to be thin. The following statement links normal and thin:

'Because I think she does not want to be fat, she wants to be thin. I think she wants a normal body.' (female, age unspecified, date unspecified)

Phillips and Hill (1998) found that heavier girls were more likely to be socially rejected, to be perceived as unattractive and to experience feelings of isolation, strengthening the argument that being fat can result in being ostracised. These notions are covered or masked with superficial and patronising beliefs that being overweight cannot be controlled and that appearance is not important. Not only does this indicate to what extent the thin ideal is already entrenched into the minds of preadolescent girls but also to what extent messages that try to counter the superiority of the thin ideal have failed.

\section{Thin means tidier, popular, smarter and leadership potential}

When describing the girls in the photographs, the thinner girl was perceived in more positive ways. Respondents assigned more positive personality traits to the thin girl.

Previous studies have concluded that thinner persons are more liked, perceived to be more intellectual, more social, more attractive and even kinder (Hill \& Silver 1995). 
In this study, the thin girl was perceived as more attractive than the heavier girl, and this held for all the respondents.

The majority of girls in the sample also had aspirations to be like the thin girl:

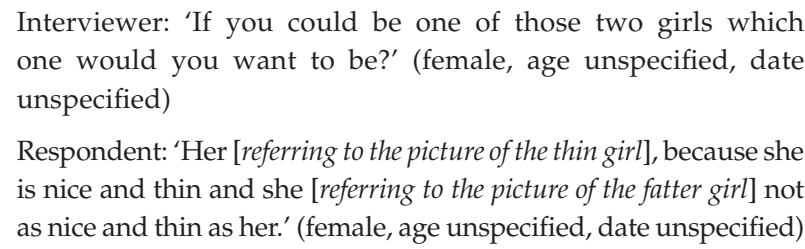

Respondent: 'Her [referring to the picture of the thin girl], because she is nice and thin and she [referring to the picture of the fatter girl] not as nice and thin as her.' (female, age unspecified, date unspecified)

The thin girl was also seen as more popular, and the fatter girl only gained a bit of popularity when she was with the thinner girl.

The thin girl was seen as popular, pretty and having more friends. The following illustrates the point:

Interviewer: 'Why do you think she is the most popular? [referring to thin girl in the picture]' (female, age unspecified, date unspecified)

Respondent: 'Because she is pretty. She has a lot of friends.'

Interviewer: 'And ... [referring to the heavier girl].' (female, age unspecified, date unspecified).

Respondent: 'Nobody likes her. Only one friend likes her.' (female, age unspecified, date unspecified)

Other than attractiveness and popularity, the thinner girl was also more highly associated with positive traits such as tidiness, kindness, friendliness and even leadership qualities.

The latter is illustrated by the following responses:

'She will probably be popular because she is good in sport or popular, because she is a leader. I think she is a leader.' (female, age unspecified, date unspecified)

'I think she has a very friendly personality.' (female, age unspecified, date unspecified)

'She is cute and tidy.' (female, age unspecified, date unspecified)

The thin girl was also perceived to be clever and favoured by the teacher, mostly because of her perceived intellect and attractiveness. One respondent remarked:

'Because sometimes people love beautiful people ... My mother she is also a teacher, she loves the most beautiful girl in her class.' (female, age unspecified, date unspecified)

The latter supports the impact which parents' thinking have on the preadolescents.

With regard to intellect, the thin girl was described as clever and bright:

'She looks very well behaved and stuff and she looks like she will do her work more than she would play around in class.' (female, age unspecified, date unspecified)

'She does good work. I think she is not naughty.' (female, age unspecified, date unspecified)
Intellect and being the teacher's favourite were also attributes given to the fatter girl. The contexts that they were given, however, differed. The girls who thought the fatter girl was the teacher's favourite attributed it to the fact that the teacher felt sorry for the fat girl. It was a discourse of pity that led to her being the teacher's favourite.

These findings support research, which has concluded that thinner persons are more liked, perceived to be more intellectual, more social and healthier (Grogan 2008; Hill \& Silver 1995; Rodgers et al. 2019; Tiggemann \& Rothblum 1988).

A discourse regarding romantic relationships emerged from one of the girls. She was of the opinion that if the fatter girl had any boys interested in her, they would also be fat.

The latter observation coincides with a study conducted by Philip and Hill (1998) who found in their study, which focussed on obese preadolescents and peer acceptance, that more than half of all obese and overweight children judged themselves as unattractive, and the latter was supported by their peers.

The finding deserves further research as interestingly the girl who expressed the view that overweight people are romantically interested in other overweight people could be classified as slightly overweight herself.

She generally referred to herself as less attractive in the interview and possibly thinks she is not capable of generating interest from others unless they are perceived as unattractive.

It is possible that she feels others who are overweight are perhaps more equal to her in terms of attractiveness and social acceptance, making the possibility for a relationship more likely.

The heavier girl was also described as less clever, less popular and less kind in comparison with the thin girl.

In addition, the heavier girl was also associated with traits such as being a 'rough girl' and 'strict and bossy', whilst no such traits were associated with the thinner girl. The heavier girl was also perceived to be naughty in class and as a girl 'who never does her work right'. The perceptions reflect the dominance of patriarchal notions as to how the female body should 'look'. The 'heavier' girl's body disrupts dominant societal notions of the aspirational female physique. The body that disrupts patriarchal notions of an aspirational female body is thus also ascribed to negative personality traits and behaviours such as bossy and rough. Boys and men with the same traits and possibly 'thin' girls would be described as leaders, assertive and decisive.

\section{Teasing because you are fat}

The prevalence of teasing has been found to be high amongst pre-adolescents and adolescents (Kostanski \& Gullone 2007; Levers-Landis et al. 2019). 
The current research also found that the topic of teasing was one to which the majority of girls could relate to, either directly (having themselves being teased) or indirectly (knowing someone who was being teased).

The scenario was posed very broadly to participants. They were informed that both girls in the pictures are being teased at school and asked to describe what they think this is.

The majority of participants immediately referred to the heavier girl and said that she was often being teased. They were hesitant to say that it was mainly because of her weight and would often say that it was because of the way she dressed (although both girls wore school uniforms) and when elaborating they also referred to her weight. This once again indicates that the girls felt that it was not appropriate to explicitly state that someone is fat or overweight. The following illustrates the point:

Interviewer: 'Why do you say they tease Portia?'

Respondent: 'Mostly it's just because they do not like her.' (female, age unspecified, date unspecified)

Interviewer: 'Why do you think that is?'

Respondent: 'Maybe ... she's fat and maybe she's stupid or something like that...' (female, age unspecified, date unspecified)

Similarly, another respondent also stated:

Interviewer: 'Why do you say they tease her?'

Respondent: 'Because she just never does her work right ... Also, maybe, because she is maybe just a little fat.' (female, age unspecified, date unspecified)

\section{Another respondent:}

'Because they think she is the ugliest one in class, or maybe they do not want to like her. Or because maybe she is fat, and she has big feet.' (female, age unspecified, date unspecified)

These responses indicate how cautious the respondents were to mention weight as a contributor to being negatively evaluated. This indicates that respondents know that being fat results in being socially rejected; however, stating this explicitly will go against the grain of their religious convictions (that all God's children are beautiful) and the socially accepted notion that all person should be accepted, irrespective of appearance.

When asked why the thinner girl was being teased, the respondent's verbatim responses were as follows:

'Because many people don't like girls if they are beautiful ... maybe they are jealous.' (female, age unspecified, date unspecified)

Interestingly, the thin girl is teased because she is 'beautiful'. The perception that thin is beautiful still holds in the discourse and that they 'are jealous', which indicates that the teasers also wish to be thin and thus beautiful.

Teasing, as the literature indicates, is most often related to a child's physical appearance (Kostanski \& Gullone 2007;
Lever-Landers et al. 2019; Vander, Wal \& Thelen 2000), and in the current research, it is relevant for both the thin and heavier girl notwithstanding underpinned by particular notions of beauty.

Kostanski and Gullone (2007) concluded that teasing has a negative effect on children's body image, and that children who are overweight are most likely to be victimised, but interestingly children who are perceived as being underweight are also teased but for very different reasons.

The issue of teasing was one the girls explained elaborately. These descriptions mainly related to the type of teasing and the perceived effect it had on the girl being teased. Many of the girls also shared examples from girls they know who are being teased or shared information that they themselves were being teased.

The teasing abuses were mostly on being overweight and it was like name calling but, in some instances, also physical hurtful teasing. Warm's (1997) research spoke of hurtful teasing, which included acts of physical aggression:

'They will say she is the Oros man and all that stuff, because the Oros man is very round you know. And they will maybe say she is fat and all that stuff.' (female, age unspecified, date unspecified)

'They call her fatty.'

'Yes, there is a girl in my class, she is very fat, and they tease her. They will say: "Hey [girl's name] you are too fat to move your desk".' (female, age unspecified, date unspecified)

'I think they will say that she is too fat and make jokes about her.' (female, age unspecified, date unspecified)

'They say, you are ugly, and you are fat.' (female, age unspecified, date unspecified)

Examples of hurtful teasing were also mentioned:

'Maybe they pull her hair. It all depends on what the children are like. There are some kind, some bad, some nasty; it could be something like that.' (female, age unspecified, date unspecified)

The literature shows that peer teasing can contribute to a negative self-perception, but that it is also seen as 'harmless' in some instances. However, the impact of teasing as experienced is what often leads to body dissatisfaction as some children can experience the taunting as extremely negative and may view the teasing as being truthful aspects about themselves (Cattarin \& Thompson 1994; Kostanski \& Gullone 2007; Warm 1997). A University of Nebraska-Lincoln (2010) study has concluded that when preteens are taunted about their weight, and it can affect them 'profoundly'.

\section{A lifelong diet}

Hill (1993) found that girls are often drawn to ways in which they control their weight as this contributes to an improved sense of self-worth. This finding led Hill and Pallin to investigate the effects of dieting awareness on self-worth in 8-year-old girls. They found that a higher BMI and lower self-worth were very highly correlated with overall 
dieting awareness, although a causal direction could not be established. In a Spanish study, it was found that more young girls aspired to be thinner than did boys. The study also found that children in the age category 12-14 years with a 'healthy' weight presented with a higher self-esteem than those who were classified as overweight, and the latter's selfesteem were higher than the participants who were in the obese category (Becerra et al. 2015).

The current research also investigated dieting awareness amongst the girls and found that all but one girl knew what the word diet meant and what activities it entailed and could give anecdotal evidence of a significant other engaging in dieting behaviour or personal accounts of engaging in dieting. Some of these responses included the following:

'Diet means you do not like to be fat and drink all those cool drinks, like Coke Zero and diet cold drinks, but I do not really drink them.' (female, age unspecified, date unspecified)

'Diet mean you eat stuff that makes you thinner and you also go to the gym.' (female, age unspecified, date unspecified)

It means when you eat healthy food to make you thin.' (female, age unspecified, date unspecified)

As the verbatim excerpts illustrate, the majority of the girls gave a definition of dieting that mostly involves restrictive food intake. Other respondents also stated that dieting requires eating 'less sweets' and 'less potatoes because, sometimes when you eat a lot of potatoes you might get too fat'.

These girls are clearly aware of what dieting entails, and that certain foods are in a no-go zone and should be avoided.

These 9-12-year-old girls were also asked where they acquired their knowledge of dieting and the majority stated that their mothers or aunts were either engaging in dieting behaviour or conveyed a diet-related message to the girl.

This is in accordance with the finding of Kichler and Crowther (2001) that the role of the mother in the child's body satisfaction is prominent as she herself is pressured to be thin. The role of the mother has also been significant in a number of studies investigating body image satisfaction and dieting behaviour. A mother who engages in and models dieting behaviour is likely to have a daughter who will follow this pattern and mirror body image satisfaction similar to that of her mother (Ogle \& Damhorst 2003; Spitzack 1990).

It has also been established that if a mother has an eating disorder or had previously been diagnosed with an eating disorder, her children had higher chances of having symptoms of eating disorder. The chances are also high that her children would indulge in emotional eating (Allen et al. 2014).

Girls were asked if they themselves have engaged in dieting behaviour. The majority stated 'no', but that their mother, aunt or someone they knew had been on a diet before.
However, these girls have been or will continue to be on what can be classified as lifelong diet as they are aware of what measures are needed to achieve a thin ideal.

Although they stated not having engaged in 'dieting', their personal accounts of what dieting is reflect a lifelong diet that is deeply embedded in a commitment to a societal discourse and pressure to remain a thin body.

Hill and Pallin (1998) found in their study, examining dieting awareness in 8-year-old girls, that girls were more likely to attribute dieting behaviour to a fictional character than admit dieting practices of their own. The same may be true in this instance.

Those who stated that they had been on diets articulated it as follows:

'I wanted to lose weight. I was a fat child when I was in grade 3. I was a very fat child. Now I am fine. I drank a special tea ... I lost $4 \mathrm{~kg}$ while I was busy on that.' (female, age unspecified, date unspecified)

These accounts are described by the girls in a very mature manner and provide insight into the manner in which dieting is perceived as a normal behaviour to attain a certain physical idea.

These accounts are disconcerting, as the girls described the onset of their dieting at a very young age, in this instance 9 years old. The early onset of dieting is a concern, as dieting is a strong predictor of overeating later in life, and in more certain cases, the development of eating disorders (Kostanski \& Gullone 1999; Sinton \& Birch 2005).

In line with the high levels of dieting awareness, the girls also stated that the heavier girl in the picture would be happier if she lost weight and offered a variety of ways in which she could achieve this. Some responses included the following:

'I think that she must gym and eat less food.' (female, age unspecified, date unspecified)

These suggestions like the others referred previously contradict the polite response to body image. In addition, these suggestions coincide with their definitions of what dieting means and again illustrates that dieting is perceived as an acceptable manner to attain a thinner body, which will be accepted by peers and which will contribute to overall happiness. However, the early onset of dieting and being aware of dieting practices can lead to body dissatisfaction and even disordered eating before the onset of adolescence.

\section{Body concerns}

The majority of the girls stated that if they could choose they would be like the thinner girl in the picture, which can be linked with the figure preference task of selecting a thinner body ideal but, as previously discussed, the majority of the girls also stated that body size is not necessarily important to 
them at this stage, strengthening the rhetorical anomalies expressed by the girls. The thinner girl was also selected as the preferred person to be like as she was described as more popular and attractive. One girl, who expressed body image satisfaction, stated that she is more like the heavier girl because:

'I am not popular, so I am more like her. I can eat what I want and I do not really get fat, but I am not popular.' (female, age unspecified, date unspecified)

The latter illustrated that a simple figure preference task does not conclude that choosing a slimmer figure than one's own means that the person making the selection strives to attain a similar figure. In this case, it is based on what the thinner person is associated with and represents, that is popularity.

Of the 11 girls who were interviewed, three girls experienced extreme body dissatisfaction, whilst the remaining girls expressed conflicting instances of body satisfaction and body dissatisfaction.

It is important to note that although not reporting extreme body dissatisfaction with regard to body image, many of the girls nonetheless associated negative attributes to the fat girl. They communicated that it is important to prevent oneself from becoming fat. One may speculate that if these views are already entrenched in preadolescence, the likelihood will increase of experiencing body image dissatisfaction when dealing with a changing body in adolescence. Evans et al. (2013) in a study of girls aged between 7 and 11 years found that embracing the thin body as ideal was a predictor of 'disordered' eating attitudes.

\section{Further discussion and concluding remarks}

The study was exploratory and aimed at providing a broad indication of the experience of South African preadolescent girls with regard to body and dieting concerns. There was no difference in the voices of the black girls and the white girls in relation to the topic. This could be attributed to the fact that all the girls attended similar schools, and all the girls lived in historically white suburbs. The sample was small, and it is possible that the sample size meant that class was the dominant variable.

The overall results indicate that the girls have at this young age internalised dominant patriarchal notions of what it means to be female. There is no doubt that the gendered thinness ideal is integrally linked to stereotypical notions of what it means to be female. Females who do not conform to the ideal female body of being thin and present with a 'disruptive physique' are labelled with negative personality attributes. Thinness is thus not an end in itself but leads to these girls assimilating and conforming to what it means to be a woman in a patriarchal society. Girls also spoke of the issue that thinness will be attractive to boys. The dominance of heterosexuality in the quest to be 'woman' and be what men desire supports much previous research. The girls also used words, such as 'sexy', to describe a thin girl, and the sexualisation of the female body 'for men' prior to adolescence was prevalent in this research.

Girls and women also socialised to not be confrontational in how they engage with others. Thus, what has been labelled as the 'polite' discourse in this research is contradictory to what they have internalised when probed. The 'polite discourse' is linked to the women and girls being 'well behaved' and not giving voice to what they actually believe.

The reference to the role of mothers in relation to dieting concerns and body image of preadolescent girls in South Africa needs to be further investigated as the role of the mother in relation to these girls' dieting concerns emerged from the data. This is similar to previous research, which indicated that pre-teen girls' dieting knowledge was often linked to what they knew about their mothers' dieting behaviour (Hill, Weaver \& Blundell 1990).

This research should be expanded with a broader sample, and a discourse analysis on the talk would yield more insightful results compared with the thematic analysis that was conducted.

The girls were from one province and from similar schools.

The findings are not generalisable to the South African preadolescent female population but serve as a foundation for future research.

In the interpretation of the results, there is caution and the choice has been to present the finding and not 'over interpret'. However, this research could provide baseline data for a bigger, more diverse representative sample across additional provinces in the country.

The following interventions are suggested: The literature in the form of children's books, which celebrate various body shapes and teach a measure of tolerance and respect, should be encouraged and included in the school curriculum. There should be workshops for mothers and girls, which encourage positive attitudes towards body image and dieting. From the current research, it is clear that the high prevalence of teasing which overweight children experience calls for intervention, as well as the early onset of food restriction should be engaged with in the school curriculum.

\section{Acknowledgements}

The author acknowledges Elna Smit for collecting all the data, which was for a master's degree.

This article represents a substantial reworking of a section from the thesis of Elna Naomi Smit, 2011, 'Body and dieting 
concerns of preadolescent South African girl children', submitted in partial fulfilment of the degree Master of Arts (Research Psychology) in the Department of Psychology, University of Pretoria, under the supervision of Prof. Dr Cheryl Potgieter.

\section{Competing interests}

The author declares that she has no financial or personal relationships that may have inappropriately influenced her in writing this research article.

\section{Author's contribution}

C.P. is the sole author of this research article.

\section{Funding information}

This research received no specific grant from any funding agency in the public, commercial or not-for-profit sectors.

\section{Data availability}

No new data were collected or analysed for the article. This article was part of a master's degree.

\section{Disclaimer}

The views and opinions expressed in this article are those of the author and do not necessarily reflect the official policy or position of any affiliated agency of the author.

\section{References}

Allen, K.L., Gibson, L.Y., McLean, N.J., Davis, E.A. \& Byrne, S.M., 2014, 'Maternal and family factors and child eating pathology: Risk and protective relationships', Journal of Eating Disorders 2, 11. https://doi.org/10.1186/2050-2974-2-11

Barter, C. \& Renold, E., 2000, “I wanna tell you a story”: Exploring the application of vignettes in qualitative research with children and young people', International Journal of Research Methodology 3(4), 307-323. https://doi. org/10.1080/13645570050178594

Becerra, M.A.O., Muros, J.J., Cuadros, J.P., Sánchez, J.A.M. \& González, M.C., 2015 'Influence of BMI on self-esteem of children aged 12-14 years', Anales de Pediatría 83, 311-317. https://doi.org/10.1016/j.anpede.2014.11.003

Berge, J.M., Maclehose, R., Loth, K.A., Eisenberg, M., Bucchianeri, M.M. \& NeumarkSztainer, D., 2013, 'Parent conversations about healthful eating and weight: Associations with adolescent disordered eating behaviors', JAMA Pediatrics 167(8), 746-753. https://doi.org/10.1001/jamapediatrics.2013.78

Brinkmann, S. \& Kvale, S., 2008, 'Ethics in qualitative research', in C. Willig \& W. Stainton-Rogers (eds.), The Sage handbook of qualitative research in psychology, pp. 263-279, Sage, London.

Brown, F. \& Slaughter, V., 2011, 'Normal body, beautiful body: Discrepant perceptions reveal a pervasive 'thin ideal' from childhood to adulthood', Body Image 8(2), 119-125.

Cattarin, J.A. \& Thompson, J.K., 1994, 'A three-year longitudinal study of body image, eating disturbance, and general psychological functioning in adolescent females' Eating Disorders: The Journal of Treatment and Prevention 2(2), 114-125. https:// doi.org/10.1080/10640269408249107

Collins, M., 1991, 'Body figure perceptions and preferences among preadolescent children', International Journal of Eating Disorders 10, 199-208. https://doi. org/10.1002/1098-108X(199103)10:2<199::AID-EAT2260100209>3.0.CO;2-D

Evans, E.H., Tovée, M.J., Boothroyd, L.G. \& Drewett, R.F., 2013, ‘Body dissatisfaction and disordered eating attitudes in 7 to 11 year-old girls: Testing a sociocultural model', Body Image 10(1), 8-15. https://doi.org/10.1016/j.bodyim.2012. 10.001

Fereday, J. \& Muir-Cochrane, E., 2006, 'Demonstrating rigor using thematic analysis: A hybrid approach of inductive and deductive coding and theme development', International Journal of Qualitative Methods 5(1), 1-11. https:// doi.org/10.1177/160940690600500107

Finch, J., 1987, 'The vignette technique in survey research', Sociology 21, 105-114. https://doi.org/10.1177/0038038587021001008
Gourlay, A., Mshana, G., Birdthistle, I., Bulugu, G., Zaba, B. \& Urassa, M., 2014, 'Using vignettes in qualitative research to explore barriers and facilitating factors to the uptake of prevention of mother-to-child transmission services in rural Tanzania: A critical analysis', BMC Medical Research Methodology 14, 21. ISSN 1471-2288. https://doi.org/10.1186/1471-2288-14-21

Grogan, S., 2008, Body Image: Understanding body dissatisfaction in men, women and children, 2nd edn., Routledge, New York, NY.

Hansson, L.M. \& Rasmussen, F., 2010, 'Predictors of 10-year-olds' obesity stereotypes: A population-based study', International Journal of Pediatric Obesity 5(1), 25-33. https://doi.org/10.3109/17477160902957141

Hazel, N., 1995, Elicitation techniques with young people, Social Research Update, 12, University of Surrey, Surrey.

Hill, A., 1993, 'Pre-adolescent dieting: Implications for eating disorders', International Review of Psychiatry 5, 87-100. https://doi.org/10.3109/09540269309028297

Hill, A.J. \& Pallin, V., 1998, 'Dieting awareness and low self-worth: Related issues in 8-year-old girls', International Journal of Eating Disorders 24, 405-413. https:// doi.org/10.1002/(SICI)1098-108X(199812)24:4<405::AID-EAT7>3.0.CO;2-D

Hill, A.J. \& Silver, E.K., 1995, 'Fat, friendless and unhealthy: Nine-year old children's perceptions of body shape stereotypes', International Journal of Obesity 19, 423-430.

Hill, A.J., Weaver, C. \& Blundell, J.E., 1990, 'Dieting concerns of 10- year old girls and their mothers', British Journal of Clinical Psychology 29, 346-348. https://doi. org/10.1111/j.2044-8260.1990.tb00894.x

Hutchinson, M., 1985, Transforming body image, Crossing Press, Freedom.

Kichler, J.C. \& Crowther, J.H., 2001, 'The effects of maternal modelling and negative familial communication on women's eating attitudes and body image', Behaviour Therapy 32, 443-457. https://doi.org/10.1016/S0005-7894(01)80030-7

Kostanski, M. \& Gullone, E., 1999, 'Dieting and body image in the child's world: Conceptualisation and behaviour', The Journal of Genetic Psychology 160(4), 488-499. https://doi.org/10.1080/00221329909595561

Kostanski, M. \& Gullone, E., 2007, 'The impact of teasing on children's body image', Journal of Child and Family Studies 16, 307-319. https://doi.org/10.1007/s10826006-9087-0

Lawler, M. \& Nixon, E., 2011, 'Body dissatisfaction among adolescent boys and girls: The effects of body mass, peer appearance culture and internalization of appearance ideals', Journal of Youth and Adolescence 40(1), 59-71. https://doi. org/10.1007/s10964-009-9500-2

Lawrence, C. \& Thelen, M., 1995, 'Body image, dieting, and self-concept: Their relation in African-American and Caucasian children', Journal of Clinical Child Psychology 24, 41-48. https://doi.org/10.1207/s15374424jccp2401_5

Lawrie, Z., Sullivan, E.A., Davies, P.S.W. \& Hill, R.J., 2006, 'Media influence on the body image of children and adolescents', Eating disorders 14, 355-364. https://doi. org/10.1080/10640260600952506

Levers-Landis, C.E., Dykstra, C., Uli, N. \& O'Riordan, M.A., 2019, 'Weight-related teasing of adolescents who are primarily obese: Roles of sociocultural attitudes towards appearance and physical activity self-efficacy', International Journal of Environmental Research and Public Health 16(9), 1540. https://doi.org/10.3390/ ijerph16091540

Levine, M. \& Smolak, L., 1996, 'Media as a context for the development of disordered eating', in L. Smolak, M. Levine \& R. Striegel-Moore (eds.), The developmental psychopathology of eating disorders, pp. 183-204, Lawrence Erlbaum, Hillsdale, NJ.

Meyer, W.F. \& Van Ede, D.M., 2001, 'Ontwikkelingsteorieë', in D.A. Louw, D.M. Van Ede \& A.E. Louw (eds.), Menslike ontwikkeling, 3rd edn., Kagiso Tersiêr, Pretoria.

Neves, C.M., Cipriani, F.M., Meireles, J., Morgado, F. \& Ferreira, M., 2017, 'Body image in childhood: An intergrative literature review', Revista paulista de pediatria: Orgoa official da Sociedade de Pediatria de Sao Paulo 35(3), 331-339. https://doi org/10590/1984-0462/;2017;35;3;00002

Ogle, J.P. \& Damhorst, M.L., 2003, 'Mothers and daughters. Interpersonal approaches to body and dieting', Journal of Family Issues 24(4), 448-487. https://doi. to body and dieting', Journal of
org/10.1177/0192513X02250826

Patton, M.Q., 2002, Qualitative research and evaluation methods, 3rd edn., Sage, Thousand Oaks, CA.

Pedro, T.M., Micklesfield, L.K., Kahn, K., Tollman, S.M., Pettifor, J.M. \& Norris, S.A. 2016, 'Body image satisfaction, eating attitudes and perceptions of female body silhouettes in rural South African adolescents', PLoS One 11(5), e0154784. https:// doi.org/10.1371/journal.pone.01547

Petersen, C.D., Norris, S.A., Pettifor, J.M. \& MacKeown, J.M., 2006, 'Eating attitudes in a group of 11-year-old urban South African girls', South African Journal of Clinical Nutrition 19(2), 80-85. https://doi.org/10.1080/16070658.2006. 11734096

Phillips, R.G. \& Hill, A.J., 1998, 'Fat, plain, but not friendless: Self-esteem and peer acceptance of obese pre-adolescent girls', International Journal of Obesity 22, 287-293. https://doi.org/10.1038/sj.ijo.0800582

Pine, K.J., 2001, 'Children's perceptions of body shape: A thinness bias in preadolescent girls and associations with femininity', Clinical Child Psychology and Psychiatry 6(4), 519-536. https://doi.org/10.1177/1359104501006004006

Ricciardelli, L.A. \& McCabe, M.P., 2001, 'Children's body image concerns and eating disturbance: A review of the literature', Clinical Psychology Review 21(3), 325-344. https://doi.org/10.1016/S0272-7358(99)00051-3

Rodgers, R.F., Wertheim, E.H., Damian, S.R., Gregg, K.J. \& Paxton, S.J., 2019 'A qualitative, prospective study of children's understanding of weight gain', British bjournal of Deve 
Russo, D. \& Spahr, A., 2011, 'Raising healthy families in a weight - Obsessed culture', Social Work Today 11(4), 20.

Sinton, M.M. \& Birch, L.L., 2005, 'Weight status and psychosocial factors predict the emergence of dieting in preadolescent girls', International Journal of Eating Disorders 38(4), 346-354. https://doi.org/10.1002/eat.20176

Spangler, D.L., 2002, 'Testing the cognitive model of eating disorders: The role of dysfunctional beliefs and appearance', Behaviour Therapy 33, 87-105. https:// doi.org/10.1016/S0005-7894(02)80007-7

Spitzack, C., 1990, Confessing excess: Women and the politics of body reduction, State University of New York Press, Albany, NY.

Stice, E., Maxfield, J. \& Wells, T., 2003, 'Adverse effects of social pressure to be thin on young women: An experimental investigation of the effects of "fat talk"', Internationa Journal of Eating Disorders 34, 108-117. https://doi.org/10.1002/eat.10171

Thelen, M.H. \& Cormier, J.F., 1995, 'Desire to be thinner and weight contro among children and their parents', Behaviour Therapy 26, 85-99. https://doi. org/10.1016/S0005-7894(05)80084-X
Tiggemann, M. \& Rothblum, E.D., 1988, 'Gender differences in social consequences of perceived overweight in the United States and Australia', Sex Roles 18, 75-86. https://doi.org/10.1007/BF00288018

Trekels, J. \& Eggermont, S., 2017, 'Beauty is good: The appearance culture, the internalization of appearance ideals, and dysfunctional appearance beliefs among tweens', Human Communication Research 43(2), 173-192. https://doi. org/10.1111/hcre.12100

University of Nebraska-Lincoln, 2010, 'Teasing about weight can affect pre-teens profoundly, study suggests', ScienceDaily, viewed 05 August 2020, from www. sciencedaily.com/releases/2010/09/100907163521.htm.

Vander Wal, J.S. \& Thelen, M.H., 2000, 'Eating and body image concerns among obese and non-obese children', Addictive Behaviours 25, 775-778. https://doi. org/10.1016/S0306-4603(00)00061-7

Warm, T.R., 1997, 'The role of teasing in development and vice versa', Journal of Developmental and Behavioural Paediatrics 18, 97-101. https://doi.org/10.1097/ 00004703-199704000-00004 